\title{
A THEORETICAL INTEGRATION OF GIG ECONOMY: ADVANCING OPPORTUNITY, CHALLENGES AND GROWTH
}

\author{
Bhanu Mati Doshi and Hitesh Tikyani \\ Assistant Professor, Vivekananda Global University, Jaipur, Rajasthan, India
}

\begin{abstract}
The gig economy is a source of influence in today's generation of professionals with the recent downsizing of talented professionals and the power of globalisation to create jobs for more underdeveloped countries. The effect of the gig economy at work is very much it has totally altered the way individuals are engaged at work and at work and felt through industries. The way our economy works has brought a radical change. The gig economy is quickly evolving in this situation as a gig economy. Relief, giving millions of Indians job opportunities. For businesses, a gig economy is cost-effective, provided that they can handle temporary staff, According to client requirements or business needs, resulting in administrative and administrative savings Costs of compliance. This system enables entrepreneurs and smaller businesses to exploit companies Professionals as required. The opportunities and difficulties of gig work are also discussed in this article in India and the ways in which it can prove to be a provider for people with good job opportunities. Ultimately, the article gives some major policy plans for the future for the development and advancement of jobs in the gig economy.
\end{abstract}

Key words: gig economy, Labour, gig work, Freelancer.

Cite this Article: Bhanu Mati Doshi and Hitesh Tikyani, A Theoretical Integration of GIG Economy: Advancing Opportunity, Challenges and Growth, International Journal of Management (IJM), 11(12), 2020, pp. 3013-3019.

http://iaeme.com/Home/issue/IJM?Volume=11\&Issue $=12$

\section{INTRODUCTION}

Recent developments in the Indian economy shows opportunities and challenges for managing Swidely shared economic prosperity in a fluctuating workers market. New opportunities, but also new legislative, legal and public policy issues, are created by the emergence of nontraditional and contingent employment connections, fostered in part by new technology platforms. Online technologies and applications are now being used by customers and staff alike to contract for specific, on-demand services such as cleaning, handiwork, shopping, cooking, driving, and remodelling. These innovations constitute what has been referred to as the "online gig" or "on demand" economy, where work takes place rather than in an ongoing 
relationship with a single employer in a series of one-off gigs. Gig work is believed to have reemerged as a result of The financial crisis of 2008, when many workers found themselves Laid off during the time and started searching for avenues That would allow them to add their low income and low income to their A drop in savings. Companies have fulfilled this demand by Which have incorporated gig work or part-time work, enabling a gradual transition from the old full-time workforce model to a new model which focuses on temporary and temporary ondemand flexible jobs. The present business climate is often referred to as India's "Fourth Industrial Revolution". It has reshaped our past thinking processes and changed the conventional perception, such as how individuals communicate with businesses, also creating a modern business climate that is very professional. Then, today technology as a method to replace older working modes at a rising pace and with an ever-growing The government of India has welcomed the quest for profitability in an increasingly competitive environment. Advantages with newer open arms technology. Just as it is for every interconnected entity scheme, In the aftermath of these developments, variables such as labour markets have also changed dramatically.

\subsection{Recent Regulatory developments in India}

Gig economy employee regulations can come in various forms. There have been recent developments in offering some benefits through certain regulatory provisions to the gig economy employees. Businesses belonging to the gig economy will not be pushed to contribute to social security cover for their staff, according to the news article. The government is preparing, instead, to provide medical treatment to gig economy workers at a subsidised rate from the Employees' State Insurance Corporation (ESIC) hospitals and dispensaries across the country.

This will come as a relief to businesses who are not expected to bear the expense of their employees' social security. In December 2019 in the Lok Sabha, the Government introduced the Social Security Code Bill, 2019, which proposed providing social security protection for employees working in the gig economy for the first time in India. The Bill proposes that a social security fund be formed using corpus available under corporate social responsibility. This fund would provide all workers, including gig workers, with welfare benefits such as pension, medical cover, and death and disability benefits.

Gig employees are those who conduct work or engage in a work arrangement and benefit from such activities outside the conventional employer-employee relationship, according to the proposed Social Security Code Bill. Gig employees are known as unorganized workers, so they would not be eligible to collect provident fund contributions. The Government will frame a scheme to give benefits under the Employees' State Insurance scheme to gig workers. The Government will not ask for contribution from employers of gig workers, as is done in other cases.

According to yet another news report of January 20, 2020, The Government intends to bring the Goods and Services Tax Network to services professionals such as plumbers, electricians and beauticians listed on online platforms, in what could be yet another step to bring gig economy employees into the formal workforce fold.

To conclude, While the gig economy's proponents might argue that individuals will profit from flexible hours, it has its fair share of critics who might consider it a form of coercion with very little legal security. Although gig work may be a necessity for some, for others, it may be a convenient choice. In a country like India, The spectrum of gig success is multifaceted and vast. With gig work being a major player in accessing semi-formal jobs, flexible work opportunities are gaining preference. It won't be out of context to note that gig work could provide a way to access formal employment with a significant portion of the workforce that is 
young and technologically savvy. Regardless of the divergent opinions, the truth is that for a country like India that has a large population, but lack of commensurate job opportunities, the gig economy is unavoidable. It is good to note that the Government is considering placing limited legislation in place, finding a balance between the company's needs and the rising gig workforce. Let's keep our fingers crossed and witness what is in store in future.

\section{REVIEW OF LITERATURE}

Balwant Singh Mehta (2020) writes that with the advent of the gig economy, the changing nature of work around the globe, especially in India. It discusses the theoretical history debates on working with technological change and shows how the recent developments in India's job market with rising unemployment and a reduction in new jobs, the situation is very disappointing. The gig economy is quickly evolving in this situation as a gig economy.

Lepanjuuri et al. (2018) find that 4.4 per cent of adults have worked in what has become known as the gig economy in the last year, and suggest that 2.4 per cent of adults do so at least monthly. The gig economy consists of work that is transacted via platforms and delivered either locally (thus requiring the worker to be physically present) or remotely.

Gerald Friedman (2014) tells that While the rise of this 'gig' Some applaud the economy as a response to the desires of a more entrepreneurial generation, and it is more likely to be motivated by business concerns regarding lower salaries and lower wages. Advantage expenses during company downturns while also reducing their susceptibility to unfairness Lawsuits seeking dismissal. The growth of gig work calls for new social policy strategies since it shifts.

Kathuria et al. (2017) More people from developing countries have been joining the emerging task-based gig economy to perform different roles in recent years. Employers allude to the fact that women are more diligent as workers, with their customers complaining less about them, and also demand lower wages as compared to men.

Mathias (2018) on-demand service work under the gig economy is likely to be relatively more disadvantaged than crowd work. The preponderance of physical tasks requiring less skills and having fewer barriers to entry and lower requirements for digital access and capacity make it more suitable for less skilled workers, and a gendered focus on on-demand work appears to be marked by significant data challenges to measure the size of the on-demand gig economy.

Shelley (2019) gig work is likely to be experienced differently in economies that are characterized by a high level of informality and precarious working conditions, with some potential for technology platforms to contribute to incremental improvements in labour conditions in these contexts.

Mehta \& Kumar (2020) Heavy dependence on Internet connectivity and recognition of gig work has increased manifold, so much so that it has begun to be counted among essential services. On-demand gig workers across the world are operating at the frontline, transporting people and delivering essential goods at their doors. Some gig workers stay at home and face financial ruin, while others continue working by putting their life at risk.

Kallenburg and Dunn (2016) gig economies have many benefits, freelancers should ensure that they are aware of the risks. Not all freelancing companies conduct business in the same way. Some companies, such as Upwork, allow the freelancer to choose their jobs, taking a percentage of the revenue earned for each job, while others charge a flat fee that is added to the final cost of the project.

Meijerink \& Keegan (2019) study suggested that gig working environment is characterized by three actors such as gig workers (also known as freelancers or independent contractors), the requester (clients), and intermediary platform firms. 
Roy Gobinda (2020) The mass adoption of the internet and increasing penetration of smartphones, connect online users across the countries over the digital platforms. This helps organizations share their talent needs and contact the remote online workers on digital platforms.

\section{CHALLENGES}

\subsection{Independent Contractors, Not Dependent Employees}

In the gig economy, staff are used as independent contractors instead of being given the status of an employee. Their employment is characterized by a short-term contract as opposed to permanent employment. Unlike full-time personnel, they are not included in the regular payrolls and social protection benefits (e.g., insurance, medical leave, provident fund, maternity/paternity leaves, etc.) offered by corporations. In addition, they are not involved within the sphere of national labour laws as well. This increases significant moral concerns with regard to job safety and how gig work can placed relatively low-skilled workers in a disadvantageous place with little or no negotiating power.

\subsection{No Union and Haggling Power}

Gig workers are not represented by any trade union and barely own any collective haggling power. Online platforms that enable on-demand work argue that they are neutral marketplaces that allow interaction between workers (service providers) and clients (service seekers). If this line of argument is followed, workers on these platforms would be counted as self-employed. However, a admonition that emerges here is that there are several employment conditions set by these platforms which result in the gig workers' autonomy being provisional. Numerous food delivery services assert on delivery workers wearing uniforms, while transport apps emphasize drivers maintaining good customer ratings. These companies often ask gig workers to perform responsibilities that are associated with full-time personnel, while themselves rejecting tasks to be shouldered as a manager.

\subsection{No Social and Job Safety}

Jobs in the gig economy are mostly casual or contractual or flexible whereby labours do not have any job safety, as once the task is complete their job gets over, no social shield or safety net is offered to the workers in the ever-increasing quantity of works in the gig economy. While the workers are able to achieve lifestyle aids' it is hard for them to find traditional benefits like getting salaried on time. While highly expert and well-paid freelancers can save and purchase personal insurance from the cloistered sector' workers in unorganized/informal sector are left without any protective measure, as they cannot afford insurances provided by the private sector and do not succeed as beneficiaries in those provided by the public sector. In such cases, job uncertainty united with financial uncertainty can be a source of major pressure for such workers.

\subsection{Poor Working Conditions}

In extremely poor working conditions, many gig workers can find themselves working long hours without set working hours, no safeguards against unfair dismissal, no right to redundancy compensation and no right to earn the national minimum wage, paid trips or sickness pay. As gig workers often WFH, they have a habit of to lose out on building systems and forming relations with other workforces. Female gig workers are particularly vulnerable to gender biases in payments i.e., they are less likely to be paid for doing the same tasks/jobs than men, and are also not included within the scope of laws that ensure their safety at work. (e.g., Prevention of Workplace Sexual Harassment Act, 2013). 


\subsection{Welfare Efforts}

Many gig workers might treasure themselves employed in extremely poor working conditions-long hours with no fixed employed hours, no protection against biased firing, no right to redundancy payments and no right to receive the national minimum wage, paid holidays or sickness pay. As gig workers often work from home, they tend to mislay out on building networks and creating relations with other workforces. Masculine gig workers are especially prone to facing gender biases in payments, that is, they are prone to being paid less than men for performing the same jobs, and are often not included within the sphere of laws that ensure their security at the workplace (Prevention of Workplace Sexual Harassment Act, 2013).

\subsection{Opportunity}

Remote workspaces that enable freelancing and support the gig economy work structure are slowly replacing brick and mortar buildings. survey on workplace flexibility revealed that 1 in 2 Indian employees prefer teleworking. As much as the steady but sure modification in this trend has been over the past duo of decades, simulated teams working on multiple different freelance projects enabled due to technology and collaboration tools will be the wave that the future of work will ride on. Today, 1 out of every 4 freelancers globally is from India. Stages such as Flexing it and Linkify are making it easier for them to earn on their own terms. Let's go through some steps to comprehend the area of opportunity.

\subsection{High-end technology}

Technological commotions have in many ways changed the means in which managers interrelate with their employees. A serious dimension of this change has been on the nature of work. Flexible work is gradually becoming a favoured option for urban employers. With reports screening the rise in the number of freelancers within urban spaces, many modern workplaces are also slowly shifting to this shift in working culture.

\subsection{Work-life balance}

The emerging millennial workforce, which by 2025 will account for 75 percent of the global workforce, according to the Business and Technical Women's Foundation, is driving the development of this virtual workforce. As digital natives, millennials favor working cultures that use technology to accommodate their work and family lives. This includes the preference of workplaces offering the option of freelancing with projects that suit them best.

\subsection{Super collaboration tools}

The future of work will include changing business models where technological empowerment will empower the rise of self-employment leading to a greater gig economy. The key to the success of virtually connected but geographically agnostic teams lie in deploying the right technologies that facilitates collaboration while aiding in strategy, planning, and knowledge sharing. This is what will maximize efficiency, productivity and help establish the future workplace

\subsection{Increased productivity}

The economics of freelance workers go beyond mere monetary savings. Increased productivity, which adds indirectly to profitability, is amplified with work from home workers. Entrepreneur.com stated that a telecommuter is twice as likely to be more productive as a nontelecommuter. Fifty-three percent of telecommuting workers work for more than 40 hours a week, compared to 23 percent of non-telecommuters. 


\subsection{Freelance workers are happier}

Remote workers make happier teams: The greatest advantage of flexible work hours that cannot be measured in monetary terms is a happier, less stressed and more motivated workforce. Eighty-two percent of remote freelance workers reported lower stress levels according to a study by PGI, a leading provider of software services. Such happy and stress-free employees can be a huge competitive advantage in the marketplace.

\section{CONCLUSION}

Global forces will continue to make the gig economy relevant. If individuals and organizations want to consider proactive strategies to beat the global competition, they cannot afford to ignore the freelance workforce. In fact, the gig economy has sufficiently gained momentum internationally to be a critical factor in the very near future. The recent rise of the gig economy has changed the way people think about employment. Unlike traditional employees who work under a fixed schedule, gig economy workers are free to choose their own schedule: when to work and for how long. Such flexibility poses a great challenge to gig platforms in terms of planning and committing to a service capacity. In this paper, we propose a framework to investigate how gig economy workers make labor decisions. Using data from a ridehailing platform, we develop an econometric model that accounts for sample selection, simultaneity, and endogeneity bias. We find that financial incentives have a positive effect on the decision to work and on the numbers of hours worked, confirming the positive income elasticity from the standard income effect. We also observe the influence of behavioral factors through the cumulative income and number of hours worked. The dominating effect, inertia, suggests that, the longer workers have been active so far, the more likely they will continue working and the longer period they will work. Our results also reflect a unique feature of gig economy work. While workers decide whether to work on both shift and day levels, they decide on the duration of their service on a Electronic copy available at: https://ssrn.com/abstract=3274628 Allon, Cohen, and Sinchaisri: The Impact of Behavioral and Economic Drivers on Gig Workers 30 shift basis. Finally, our numerical experiments demonstrate that gig economy platforms can benefit from incorporating our insights on labor decisions into their incentive optimization. One of the important phenomena that emerge from this paper is the existence of inertia among drivers. While we cannot conclude that all gig economy workers exhibit such a behavior, we believe that it has important implications that go beyond this study. Indeed, we believe the findings are generalizable for three reasons. First, there is nothing specific nor exclusive about the platform studied in this paper. Second, drivers working for this platform are often also working for competing platforms. Third, policies used by our industry partner are quite common in the industry. Therefore, there is a lesson to be learned about the fundamental impact of such policies. Amidst intensifying competition among providers of similar on-demand services, companies are making every effort to win over a mutual pool of workers. This paper empirically identifies several key behavioral factors that affect gig economy workers' decisions. Our research can be used to sharpen platforms' understanding on how gig economy workers make labor decisions, and ultimately improve platforms' operational decisions (e.g., sending the right offer to the right worker at the right time). This paper opens several avenues for future research. It could be interesting to validate our findings by running a controlled field experiment. Given that online platforms routinely run experiments to confirm insights, testing the income targeting and inertia effects can be of interest. A second direction is to further investigate how workers construct their reference points or targets in both financial and time dimensions, and how these targets are updated over time. This will allow companies to gain insights about the (dis)utility of working as well as understanding how workers switch between service providers. Finally, our incentive allocation is based on simple ranking arguments. Developing a more comprehensive optimization framework to optimize incentives for each 
driver in each shift under further operational constraints is also an interesting extension. The main goals of this research stream are to refine our understanding of gig economy workers and develop data-driven methods that can be used by gig platforms to efficiently motivate and strengthen their relationships with their flexible workforce.

\section{REFERENCES}

[1] Abraham, Katharine, et al. "Measuring the gig economy: Current knowledge and open issues." Measuring and Accounting for Innovation in the 21st Century (2017).

[2] Balaram, Brhmie, Josie Warden, and Fabian Wallace-Stephens. "Good Gigs: A fairer future for the UK's gig economy." London: RSA (2017).

[3] Broughton, Andrea, et al. "The experiences of individuals in the gig economy." HM Government (2018).

[4] De Stefano, Valerio. "The rise of the just-in-time workforce: On-demand work, crowdwork, and labor protection in the gig-economy." Comp. Lab. L. \& Pol'y J. 37 (2015): 471.

[5] Doshi bhanu mati "Psychological Contract Breach and Workplace Outcome: A Theoretical Integration" Test Engineering and Management 83 (2020)

[6] Gandini, Alessandro. "Labour process theory and the gig economy." Human Relations 72.6 (2019): 1039-1056.

[7] Goswami, Tulsee Giri, and Saroj Kumar Ranjan. "Green HRM: Approach to sustainability in current scenario." Journal for studies in Management and Planning 1.4 (2015): 250-259.

[8] Kuhn, Kristine M. "The Rise of the" Gig Economy" and Implications for Understanding Work and Workers." Industrial and Organizational Psychology 9.1 (2016): 157.

[9] Lepanjuuri, Katriina, Robert Wishart, and Peter Cornick. "The characteristics of those in the gig economy." Department for Business, Energy and Industrial Strategy (2018).

[10] Lobel, Orly. "The gig economy \& the future of employment and labor law." USFL Rev. 51 (2017): 51.

[11] Manyika, James, et al. "Independent work: Choice, necessity, and the gig economy." McKinsey Global Institute 2016 (2016): 1-16.

[12] Roy, Gobinda, and Avinash K. Shrivastava. "Future of Gig Economy: Opportunities and Challenges." IMI Konnect 9 (2020): 14-25.

[13] Sargeant, Malcolm. "The gig economy and the future of work." Ejournal of International and Comparative Labour Studies 6.2 (2017): 1-12.

[14] SK Ranjan, S Afroz "A systematic review of literature: Psychological Contract Breach in tourism industry and other organizations." Restaurant Business, Vol-15-Issue-7-July-2019.

[15] Stewart, Andrew, and Jim Stanford. "Regulating work in the gig economy: What are the options?." The Economic and Labour Relations Review 28.3 (2017): 420-437.

[16] Wood, Alex J., et al. "Good gig, bad gig: Autonomy and algorithmic control in the global gig economy." Work, Employment and Society 33.1 (2019): 56-75. 